\title{
Factors Influencing Glass Ceiling focus on Women Administration in Higher Education in Malaysia: A Critical
}

\author{
Sharif Uddin Ahmed Rana, Valliappan Raju
}

\begin{abstract}
Malaysia as a country has grown quite a lot over the last two decades despite the political condition often troubled with allegations of corruption but speaking economically and in social context, it can be claimed that as a country, Malaysia has fared in a decent manner and it has been able to maintain stability which has helped to elevate the progress of the nation. The social structure of Malaysia is in such a manner where there is a broad distribution of multiple ethnicities and cultures that it has been able to maintain but in accordance to the latest Gender Development Index, as till 2017, Malaysia ranks 57th among the 189 countries (http://hdr.undp.org/en/composite/GDI) and is categorized as a country with "VERY HIGH HUMAN DEVELOPMENT". The paper makes an attempt to analyze and evaluate the various factors that have direct and indirect implications in acting as factors to influence the presence of "glass ceiling" in the higher education sector with focus on women administration. The objective is to explore and identify the different reasons behind women having to struggle in a country that has such a commendable mark in the HDI where the ones leading are from generally characterized first world countries. The discussion would highlight ways as suggested and put forth by the respondents who have been exposed to "glass ceiling" in various aspects of their career from the different sources and their opinion as to how they were able to overcome and how the upcoming young generation, the women who are aspiring to join the workforce in the coming future can prepare themselves in a manner that would assist them to prepare themselves in ways that the effects and impacts of "glass ceiling" can be reduced and tackled. The role of the components from the society to have an active role in making the effects to be reduced is extremely crucial and has to be dealt with in a manner that can serve the society in the long run.
\end{abstract}

Keywords: Glass Ceiling, Malaysia, gender

\section{INTRODUCTION}

The concept of "glass ceiling", especially with regard to women in the workplace and academic sphere has gradually gained further traction over time since its inception because of its effects and implications, since the mid-1980s.The phenomenon with respect to relentless struggle of women in various aspects of life is not really an uncommon scenario that we are absolutely unaware of. The idea of gender gap is not only a third world theory as the prominence of it has been observed in developed nations as well in terms of economic disparity, social presence and it often at times cannotbe represented as numerical values. The prospects of success of an individual isindependent of the gender, that is what scientific theories have told us and have been put forth as but often at times the consideration

Revised Manuscript Received on 14 August, 2019.

Sharif Uddin Ahmed Rana, Ph.D scholar, Limkokwing University of Creative Technology, Malaysia.

Dr. Valliappan Raju, Supervisor, Limkokwing University of Creative Technology, Malaysia. for the probability of success is contingent on the gender which is nothing but simply appalling. An individual due to the gender gets exposed tocertain treatments that one would not have had to come across and it occurred only due to being of a certain gender. The reason why it is even more difficult to tackle and deal with is due to the nature of individuals to be in a state of denial and not entirely conceding to the notion that it is a prevalent concern that requires attention and evasive measures or else productive contribution can be expected to be lost out from a segment of the society that is numerically around $50 \%$ of the population in the world. The most difficult quotient is the extent to which the concept of "glass ceiling" is that, it has to be explained qualitatively, it cannot be explained up front and in quantitative terms because of the nature of the theory and dependence on subjectivity. The active role of women in all aspects of life is a truth that cannot be denied by any one since it has been prevalent due to the way how women contribute and not only limited to building a family, the apparent role of a woman as perceived by a society but the immense level of contribution from women in economic sector, medical sector, technological advancements, education sector, philosophical prowess have been able to show us how eminent is the presence of women in context of the multiple sectors. The disheartening part is, often at times, men are absolutely ignorant of the struggles of a woman and theirinability to relate with the hurdles of a woman makes it even more difficult for the women to go about in the society.

Since the inception of human civilization, the way how women have to work comparatively more in comparison to their counterpart has been a difficult phase and in the career path, the frequency of struggle being more for the women is a major concern and it owes entirely to physiological condition of the women. The presence of "glassceiling"inalmostevery aspect of life is aconcession that any and all women have made at some point of their life and there is no scope to disregard the claim in any way. The presence of "glass ceiling" in context of women administration in higher education has not been denied entirely by any of the women that we could have an interaction with, the level of obstacles to overcome "glass ceiling" and method adopted to get over their individual struggles varied among the respondents. The women who have been able to overcome the "glass ceiling" are extremely hopeful with regard to the upcoming generation having it a bit easier to overcome the obstacles of "glass ceiling" and they also feel that in case they had someone to look up to, one who would encourage, show the glimpse of light at the end of the tunnel then that perhaps

Published By:

Blue Eyes Intelligence Engineering

\& Sciences Publication

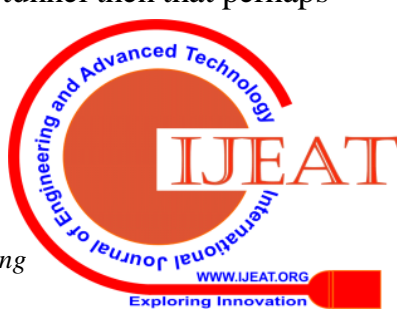




\section{FACTORS INFLUENCING GLASS CEILING FOCUS ON WOMEN ADMINISTRATION IN HIGHER EDUCATION IN MALAYSIA: A CRITICAL}

would have been able to reduce the duration to gathercourage and break the "glass ceiling" and go about with less uncertainty, while being able to handle the society in a manner that would make life a bit more convenient for them with less issues to be afraid and scared of.

\section{LITERATURE REVIEW}

The idea of "glass ceiling" was first formally brought forward in the year 1986 Wall Street Journal special report on Corporate Women as during that time the idea was limited to women pursuing leadership roles and upper positions up the hierarchy in the corporate ladder. The recognition of "glass ceilings" being a pertinent concern for the women is a much recognized issue in the status quo. The feminist movement has made enormous effort to realize various needs for women to be considered equal in the working space. The multiple literatures that have been overviewed in course of making an attempt to understand the dynamics related to "glass ceilings" pertaining to women and how it significantly affects them in their pursuit of career. A few of the major observation includes how the inherent submissive discrimination is an issue since the very inception when women initially began to work outside the house. It was a struggle for women to get rights at an earlier stage and it is nothing but depressing to at times find the uncanny similarity between equal rights of women and being similar in nature like black rights and ending concepts as treacherous like slavery. The active role of globalization and evolution of human civilization has made it clear to human beings that in order to progress forward in a manner that leads towards the civilization to serve its due purpose there is no scope to undermine half the population on the basis of gender.

The literatures put forth some common ideas irrespective of the geographical background, ethnic background and economic prowess of the region. The inherent reception of obstacles and hurdles purely on the basis of gender is a common phenomenon. The socio-economic background also at times has a role to play with respect to how one aspires to build oneself and attain certain heights in their career path. The literatures also put forth the idea that the exposure to "glass ceilings" for women cannot be identified to have any specific way to be identified and is very much case specific for each of the individuals that are discussed about or provided as examples. The narrative also reaffirms that there is a bit of commonality with respect to the source of acting as impedance, some of the similar methods and agencies that assisted the individual to overcome the "glass ceiling" encountered by each individual.

The analysis that can be derived from the literature revolves around the idea that an individual is often simply deprived of certain entitlements, in the work place or working environment only on the basis of a certain individual being a woman and how it becomes difficult for one to manage the familial responsibilities, work place adversities that can relate to superiors and peers, social ostracization at times due to being a working woman and not providing adequate attention to family, especially the children thus are termed as irresponsible mother in case any mishap happens with respect to the child or any of the household role is missed out due to commitments related to the work makes the women suffer.

\section{METHODOLOGY}

The concept of "glass ceilings" while focusing on women administration in higher education of Malaysia thus we opted to carry out Interviews to collect the experiences of individuals in terms of their encounter with any and all forms of "glass ceilings" and their opinion with regard to how they could overcome the "glass ceiling" and how they would suggest the ones i.e. female individuals who are pursuing to progress ahead in their career, what can be their area of concern, what do they need to be carefulabout and what can be done from their end to prepare themselves for the upcoming challenges in theircareerpath. Each respondent wasaskedafew common set of questions while they expressed and put forth their personal experiences which helped us to understand, analyze and evaluate the various dynamics of "glass ceiling". The respondents selected for carrying out the interview are all scholars who have been working with administration related directly with higher education and have been in the education sector of Malaysia during the course of their career which helped to give us an insight of how the sector encounters such a scenario and their insight especially with regard to the cultural and social background gives us an opportunity to have a better understanding of the set up that is exclusively focused in Malaysia. The individuals who opted in to provide interview were made well aware about the objective of the study and how we will be using the information collected for the sake of Academic Analysis only while ensuring confidentiality and ethicalgroundspertainingtothe study.

\subsection{Major Findings}

The various respondents have been kind and generous to put forth theirown view point with respect to the questions that were asked to them. The respondents were anxious and curious to share their life experiences and each one of them had their own story to share withrespect to "glass ceilings" that they have come across in the course of their career. The summary of the findings is provided below

\section{a. Not every work is suitable for you as you are a girl}

There is a general perception that when you see a girl child growing up, it is difficult to imagine the girl as an Architect or an Electrical Engineer and it has got nothing to do with the abilities of the girl but rather a submissive way in which certain gender roles are defined in the society and thus it becomes difficult for a woman who has a Bachelor's degree in Engineering to pursue a career in that sector due to the bias working against her.

\section{b. The way how the opinion of a woman is often undermined}

It is a common complain that came forth from majority of the respondents that they struggled tomake theirvoices heardinany discussion or togetawork done when a work is executed.

\section{c. The disparity in payment}

Majority of the women had their own complain that they ended up being paid less than their contemporary male colleagues despite not lagging behind in any way in terms of contribution and they had a hard time convincing their superior 
that they deserve the payment they were provided with and due to this way of treatment it ended up affecting their promotions and moving forward in the chain of hierarchy thus at times affected their motivation to work.

\section{d. $\quad$ The support from spouse}

The extent of support from the end of their spouse acted as a great motivation for individuals to work and concentrate in their career path where on multiple occasions the respondents ended upacknowledging their spouse to be their biggest support system whomotivated themtocarry on with their aspiration in pursuit of a career and major chunk of their obstacles could be worked out because of the way how their spouse stood by them or how it became more difficult to deal with a certain situation due to lack of support from spouse and from family as well

\section{e. Workplace Environment and adversity from contemporary peers}

The presence of rat race is there in any and all profession and the treatment of a woman in the workplace, whether she receives adequate assistance from her peers and colleagues has a direct effect with respect to how one can work in a certain situation and circumstance, the workplace has to recognize the issues of a woman especially the physical condition, especially during the time when she is having her period and if the organization and the workplace is ignorant about the situation and what the woman is going through and something that is not within her control then it becomes absolutely impossible for a woman to sustain in the workplace. The prominence of sexual harassment and sexism often leads towards acting as a demotivating factor for the women to continue working.

\section{f. The availability of female role models}

Many of the respondents ended up conceding that the lack of role models often acts as a factor behind women not pursuing certain types of jobs, not to mention the inherent push from society that a nurse is generally a woman and a fireman is generally a man thus when given in a leadership role, a lot of the respondents had to struggle initially since they found it difficult to be considered seriously and their instructions were not taken seriously at times as well which lead towards them ending up doubting themselves. The male chauvinism also made it difficult to break the "glass ceiling" since it confronted the dominating nature of men which often meant that the women had to take a firm stance to make their voices and opinions to be considered seriously by herpeers.

\section{DISCUSSION AND CRITICAL ANALYSIS \& RESULTS}

\subsection{General Observation}

The respondents unanimously conceded that "glass ceiling" has been encountered by them at some point of their career pursuit and in the Academic sphere even though the working culture is not similar to how the working environment functions in the corporate world but the pursuit of a woman even in the world of Academic career has the perks of its own. The way how gender roles are defined in the social context is a concern for quite a few because it becomes difficult to imagine a woman working as an engineer on the site or work in a firm as an Architect, the careers that primarily require technical attributes are often at times considered to be work more suitable for men and even in the Academic sphere when one comes across academicians related to engineering or architecture even with respect to that the individuals who pursue a career with respect to academics. The recognition with regard to role of family to help them be in a certain shape has been put forth by almost all of the respondents. The idea of being able to maintain a balance between their career and familial responsibilities especially giving birth to children has been a cause that leads towards a stagnation in the career of individuals and then being able to reintegrate to the work back again is also a concern for the individuals at times.

The way how an individual reacts and responds to certain situations also ends up defining with regard to how the woman is considered in the work place environment, the way how the individual can go about her life while maintaining the plethora of challenges and obstacles that come about both in context of her work life and personal often makes it difficult and during that time she seeks for adequate level of supportfromher family, especially from her husband and children. The physiological impacts in the life of a woman require the need for her to be treated in a way that enables her to cope up with the situation when she has to deal with her biological condition. The physiological condition of the woman would cause the woman to be in a state and condition that ends up making her go through certain scenario that are not entirely under her control in any way thus she has to be considered with regard to her condition.

The moment one tries to act in a way that is not in alignment with the general narrative and norm of the society which results in a woman to encounter challenges from various layers of entities existing in the life of the individual. The moment the stereotypes are challenged and general norm is confronted then it becomes quite difficult for one to reconcile for the way that society is expecting for one to behave and goabout and since she is not really going about that manner she has to face obstacles and it is a major issue since it goes on to make one having to reaffirm the choice of the individual so she has to go about and prove to the society how the choice made from her end is appropriate and prove to multiple entities.

Specific Observation and Analysis of situation and circumstances for women in academic administration

a. Defined Gender Roles and its implications in life of a women pursuing a career

The way how society perceives every individual to go about in terms of their career aspiration and the pursuit is often contingent on the basis of their gender. The moment a girl begins to think as to which career should she aspire to pursue then in that case she has to consider multiple factors which perhapsis not the case for the opposite gender whoincomparison have way more freedom and as unfortunate as it may sound, it owes to the gender of an individual. The accessibility of women to certain entitlements is difficult, still and it is more prominent in the conservative societies where a girl has to overcome multiple obstacles to make oneself prepared in a manner that enables an individual to go about in life in a manner and carry out work that is perhaps not identified to be work suitable for the women.

Blue Eyes Intelligence Engineering

\& Sciences Publication 


\section{FACTORS INFLUENCING GLASS CEILING FOCUS ON WOMEN ADMINISTRATION IN HIGHER EDUCATION IN MALAYSIA: A CRITICAL}

The pretext of such an opinion to be built up initiates from the moment that a toy is bought and given to a child. The probability for a boy child to be given a toy such as Barbie doll is very unlikely and for a girl child to be handed over a fire truck is also equally unlikely and there is no essential or definitive explanation for the actions to happen as such. The justification often used to rationalize the act owes to how the girl is identified as the individual who knits the family together and the one who is more into taking care of the ones around her thus the Barbie doll portraying that she is expected to go about and seek for leading a life that works behind being the organized one who keeps things in order and dedicate theireffort and time for working in a manner such that it allows one to be the way that perhaps society wants her to be. The rational for the boy child to be provided with a fire truck portrays the idea that the image that an individual who can be a fire fighter is supposedly a man as it requires masculine traits and features. The harm that it does is simply curbing down the option in terms of the career path for a woman which is plain and simply unfair and unjust. The way that a child is made to think and feel makes a kid to realize that since one is a boy then he is expected to go about their life in a certain way and it is okay for a boy to behave in certain ways and exhibit certain behavior but in the course of such an event what it ends up doing is making a kid instilled with the belief that the way how one should try and go about and behave is defined and if one does not go by then one at times is even ostracized socially. The life is made even more difficult whenthereislackof support from the parents and it is difficult to blame the parents as well; the extent to which the parents to ensure that they are considered being in the mainstream and often theyarereluctant to encourage their children if their child tries to go about their life in a manner that is not a generally perceived scenario for their child and in order to provide the very best for their child and be accepted in the society and community they tend to make themselves and their to be built up in a manner that helps them to remain in the mainstream.

As a child grows up, they gradually are influenced by their parents, siblings, contemporary peers and friends. The way how things happen in the mainstream has an impact on them to realize and recognize the way that one is expected to go about. The way how they get exposed to the genderdefinedrolesactson them toacknowledge the work that they can pursue to be engaged with and get involved in. The restriction of a child to break the stereotype and get involved with a work that might be considered not suitable or appropriate due to the gender then it becomes difficult for an individual to carry out such a work and association. The poor gender ration in the pursuit of education is an example of how we can see that engineering departments and work such as Architecture have a very low proportion of female involvement and it becomes difficult for the ones who still gather the courage to be involved then building a prosperous and successful career out of the profession related to the one that one is not expected to pursue due to perceived gender roles. The way how one has been instilled to think in a certain way acts to make one unable to even think that one can think of pursuing a career that sheis not perceived to be part of and it is not an easy task for one to survive even if one gets involved with. The struggle never ends if one just gets involved in the profession as society still keeps on reminding the individual that it is not a place or position that a woman is supposed to be at.
The struggle after being involved in a career stretches to the extent where there is undermining of the work, lack of appreciation, constant judgment, one having to get validation of work over and over again. The struggles become more imminent when a woman who has struggled so much to come and reach a certain position makes the slightest of mistakes then the level of scrutiny and criticism that befalls on an individual is nothing but plainly unjust. The set parameters that the certain physiological limitations of a woman can make it difficult for one to carry out certain tasks which is needless to be marked as discriminatory and discouraging since a girl makes herself realize that she was just not meant for the job and when she tries to break the gender stereotypes then she is made to feel ostracized and keeps on seeking for validation which does not act as an encouraging factor thus the certain defined gender roles end up prevailing more which does not help the cause of progress of women and thus the disparity enacting as well spiraling to the society since the way for one to get social validation keeps getting questioned, just being difficult. The struggles are real and given the opinions are shaped over years, make it way more difficult.

b. Discriminatory treatment - wage gap, work place environment, male chauvinism, own credibility

The work place culture and environment has impact and implications with respect to how a woman goes about doing her work and gets her objectives met and gets her plans executed. The level of hostility encountered in the workplace from the peers often makes life quite difficult for them since a work or task is at times contingent on a group to execute the plans. The idea of a woman to get a job or task done in due time while meeting up to the requirements becomes difficult and not to mention the level of animosity that is faced by a woman from herpeers which makes her difficult to complete the tasks. The lacks of specifications with regard and respect to the role and responsibility often lacksclarity. The wayhow one is assigned with a task makes it difficult for one to consider the way of getting the work done and the discriminatory conduct endsupmakingonefeelunwantedandbeing doubtfulaboutone's own abilities which is harmful for not only oneself but also the way how one ends up doubting the abilities of oneself thus resulting in making the entire scenario obscured for the individual. The way how one goes about doing a task, competing. The interviews revealed that the competitiveness in the working environment instead of encouraging a culture of enhancing the credibility of individuals made it difficult due to the men having a narrative that how can a woman perform better than them thus whenever in a state where a woman is given leadership role then she finds it difficult to get the task done especially when a team is involved given that she does not receive adequate cooperation and assistance from her peers and whenever there is a slight chance of anything to go wring then in that case she always receives the most trivialized issues from her peers thus makes it so complicated to get the work done. It is also observed that the work environment ends up making a woman demotivated to such an extent that she ends up feeling like leavingeverything.

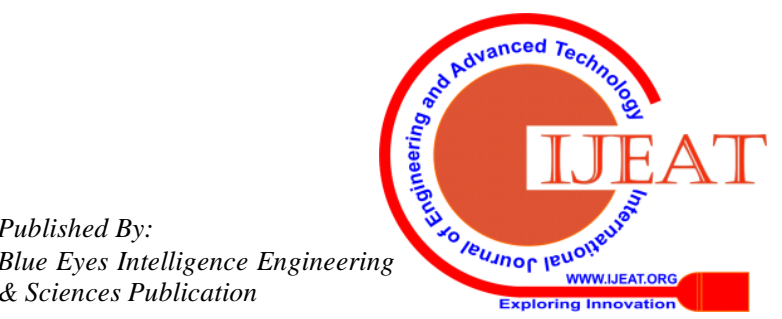


The appreciation and acknowledgement of the effort put in by individuals is necessary to be recognized to a certain degree but unfortunately a lot of the respondents conceded that there has always been a lack of appreciation from her peers and her superiors, the reward for her worknot being there but then again the extensive criticism became an overwhelming factor for her to keep on working with the same zeal and enthusiasm. The disparity in terms of the pay gap is inherently a factor that gives less incentive to a woman to carry out a task and the perception towards women being in a manner that they do not need to put effort rather get an easy way out just because of them being women also makes them identified as opportunists and ones who get their way but often do not realize the underlying effort of a woman which is nothing but simply disrespecting the effort of a woman which is shambolic. The effort that a woman has to give to get validation for the work done from her end and the way that she is acknowledged gives her reasons to put in further effort but since there is always a sense of despair and it comes with regard to her payment and promotions to move up the chain of hierarchy does not act to incentivize a woman adequately.

The working culture and environment in the corporate culture is way more toxic than the situation in the Academic sphere but the presence of "glass ceiling" is still there. The leadership roles and the prejudiced treatment in context of monetary incentives does not seem to help the essential cause in any way to make things easier for the women. The constant need for validation of work, the need to prove oneself for each and every task being completed while being on the lookout for being scrutinized for the slightest of mistakes that can be made is nothing but an excruciatingly painful as they end up beingjudgmental and doubtfulabout their own credibility.

The prospects of a woman in the chain of hierarchy also enacts to make a woman realize that the career aspiration to grow over in the career path is often encountered with "glass ceiling" where a woman is often made to feel and believe that she is not worthy of a leadership position and it is an unattainable feat to be the head of an organization thus reaffirming the anecdote that a woman is not meant to be in certain situation and condition. The hard work that a woman puts in is undermined at times since she does not get the same level of acknowledgement from her superior which demotivates a woman to give further effort in terms of her work. The pay gap being an imminent factor reflects the social build up that a woman and her work is not of the same level as that of a man despite showing on repeatedly that the quality of work is not lacking in any way and perhaps is better in terms of quality than her counterpart but on the occasion where she observes that the level of trouble she has to bear and go through to put forward for the work done by her and is not being able to receive the deserving treatment then it does not give a woman to put in her optimum effort. The leadership position when handed over to a woman, the general narrative that flies through is how a woman is unable to make a decision that is "tough" and thus she does not deserve to be in such a position which is simply ridiculous and when any plan of action does not follow its expected route then the heavy ostracization and criticism is a feature that makes the woman feel isolated even more and doubt herself and her credibility. The doubtfulness ends up affecting her decision making abilities since then a woman becomes extra cautious since she is underimmense pressure that she cannot falter ormake amistake as there are so many just waiting to pounce on her smallest of errors. There is a constant fear in the individuals that once they make a mistake how they will be recovering their image, impression and reputation and how it will reflect in the way that a certain individual is perceived and considered which is a concern foralotof the individuals.

The idea of prominence of male chauvinism is not really a new but rather an age old prevalent factor. The beginning of human civilization has observed how gender roles have been present from the very beginning where women have been identified as ones who keep the order of the house and bring up the children while their male partner when about to provide food by going out of the place where the family resided. The evolution of human civilization has made us realize that every individual has a way to contribute in the society and it is pertinent that every individual is utilized at an optimum level or else there is no point of life, that is essentially in context of social science paradigm and it is needless to say that there should be further meaning to the life of an individual rather than just being an entity that is taking care of family and bringing up children and that also bearing in mind that there is a separate feeling in terms of sense of gratification when a mother contributes in the upbringing of a child, taking care of a family, holding a family together and withstanding the multiple hardships associated with family.

Since the industrial revolution, there has been a rise in women association in the workplace which is a positive sign but social perspective towards the involvement of women in the workplace has not really been flying through especially in the Asian countries where there is a build in struggle for women to work out of their home. The implications of male chauvinism have got to do a lot in the way how women face the numerous obstacles in the work place where their male counterpart does not make it easy for them to work along them. The respondents have showcased how they had to encounter submissive and indirect chauvinism that made it difficult for them to work along and the treatment of women leading towards them being discouraged to go about their work and duties and in case that they were made to feel unwanted kept making them feel doubtful with respect to their abilities. The constant need for validation of their work makes them become exposed to certain scenario where there arises a sense of unhealthy competition that is often used by the male counterpart to feel insecure about themselves and then resulting in them going on to trouble the women which made it unbearable for some of the women to handle and tackle over the course of their so they either had to bear with it or simply leave which is indicated by the low rate of retention in the work place where the gender ratio is highly disproportionate and thus an alarming indication that if measures are not taken then productive workforce is lost out. The ideas of having a safe space can help not just retain women but enhance the overall productivity of the system that includes both men and women which currently has unnecessary animosity. 


\section{FACTORS INFLUENCING GLASS CEILING FOCUS ON WOMEN ADMINISTRATION IN HIGHER EDUCATION IN MALAYSIA: A CRITICAL}

c. The treatment of opinion, views and sayings in context of her gender not intellect

The work of a woman is often undermined and underrated plainly on the basis of the gender factor which is nothing but simply appalling since it disregards the merit of the work and focuses on the gender of an individual. The respondents often at times explicitly mentioned that they had to struggle for getting their points through as their opinions and viewpoints were not given much attention and their saying was not prioritized even though perhaps the same idea when coming from a male counterpart got way more appreciation and given loads of value which made them eventually reluctant to contribute in the discussion since their opinions ended up being lost due to the lack of adequate attention being given.

The extent of criticism when a certain action plan failed or did notachieveitsdesired goals then often at times, the women got scrutinized more in comparison to the men. The work of a women being on the receiving end of extensive critique does not help the cause of making her feel being wanted and deserving of beingincertain situationandcondition whichisneedlessto

the extent that does not recognize the merits of the work or activity which in turn could lead towards an individual being completely demotivated and not having the enthusiasm to be associated and affiliated with a certain work or activity. There is no denial that there are certain work where a due to the physiological constraints, a man would be a comparatively better choice than a woman but in the academic sphere, where the activities are more oriented towards cognitive abilities and analytical prowess of an individual, when it is observed that while granting of funding is done more to a project where there are comparatively more men than women and the project where there is lack of men that project not being provided with adequate funding on the basis that the prospects of the experiments and initiatives are less likely to be materialized thus the extent of reliability to yield productive output being contingent on the gender only reflects the fact that how the essence of patriarchy has such extent of biases towards women and are unable to provide a scenario where she can make an earnest attempt to work on something she truly believes and it also at times does not enable her to switch from a current work place that she has adapted in as she ends up wondering that once she changes her work place, what type of obstacles she might have to come across and overcome in order to survive at a new working environment thus there is a general tendency for women to not switch from a workplace where one has adjusted and adapted oneself in. The persistence of individuals to continue at the same working place over a long time ends up making them reliant on the organization that the progress in terms of the career path becomes stagnant and which does not help in furthering their progress of career.

d. Extent, effect and impact of support system contemporary peers and family

The respondents unanimously conceded that the biggest reason for them being able to continue their aspiration and pursuit owed a lot to the way how their family supported them. The need for a supportive partner has been identified as a crucial and essential part for the individuals being able to continue their career pursuit. The "glass ceiling" in terms of how family acts as a resorting agent where one can vent out and release all the hardships that one comes across and in doing so if their partner does not act as a support system who tries to ensure that no matter the situation and circumstances, the partner always stands by her in ensuring that she can move ahead in her life. The way how one woman can gather the courage to tackle the male chauvinism, the submissive antagonization from peers and colleagues, constant lack of validation of their work and having to prove oneself over and over again to prove their credibility is also a concern.

The act of giving birth has a huge impact in the life of a woman and no one can deny the extent of changes that happens in the body of a woman while she conceives and gives birth to a child. The birth of a child often at times is a phase of the life of a woman where she goes through such a transformation that often takes a toll on her in terms of her physiological condition and the way that the psychology gets shaped as well. The experience of motherhood being such a feeling that one gets to feel and believe that it is nothing but fulfilling to an individual and thus it leads one to get a sense of completeness in terms of their life. The life of a woman changes drastically whenshegivesbirthtoa child and once the baby comes to a mother's lap, she has to deal with multiple changes and even during the duration of pregnancy there are multiple hormonal changes that take place inside the body of a woman. The way how one makes an attemptintegrate back since the birth of achild requires extensive supportfrom the family. The only way how it can be easier for a woman to still continue in pursuing her career can only be thought given there is support from her partner and it makes one realize that when returning from a hiatus due to the birth of a child, the career path hits a bump and when she again returns back to the workplace, the initial stage even though is a struggle but still withadequate support from the family in terms of taking care of the child, having to look after the baby and ensuring that the baby is taken care of thus she can concentrate on her work without having to worry about the issues pertaining to her child and then having to take care of the wellbeing of the child if not shared by both the partners then it becomes really difficult for the mother to manage between her work life and her career pursuit thus it cannot be undermined that the family as a support system needs to provide the level of comfort to a woman that she can handle office work while the child is taken care of as well.

e. Inspiration and role model to look up to for an individual

The initiative from the end of a woman to go against stereotypes is not the easiest of tasks especially by someone in a semi conservative society. The eagerness of the society to being on the lookout for individuals whoever is not going alongthe mainstreamasexpectedfrom theend of the society thus it becomes extra challenging that she has to go against the social stereotype while trying to prove her own credentials and credibility while seeking for constant validation from the society for the work done by the individual. The way how society perceives the actions of individuals tends to dictate the decision making actions of an individual which leads to say that the

Published By:

Blue Eyes Intelligence Engineering \& Sciences Publication

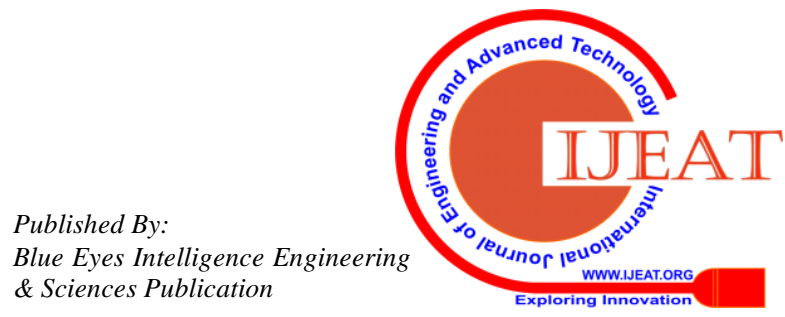


hardships have to be worked upon and only then can there be a glimpse of hope for individuals to realize that there is a certain possibility that one can try and make an attempt to go against the generally accepted mainstream that is considered to be in alignment with the general norm.

The lack of individuals who can gather the courage to try out something in life that is not in accordance to the general norm is difficult and since everyone is afraid to try out something that has not really been tried and tested garners loads of anxiety andcautiousnessamong theones whotry togoaheadin theirlives trying to seek for achieving what they have perhaps wished for but what becomes problematic for them is the idea that how much one can endure going against the way that how society considers as the right way to go about. The respondents clearly indicated that each of them have had their own share of hardships that they opted to deal with and overcome the certain obstacles and hurdles only to pursue the career path that they feel to be the right way to go by and in the course, there have been multiple obstacles and each individual had their own way of dealing with the hurdles and eventually being able to go through with them and in the course of such fighting through it has not always been that it has been in any way easy and the variation in terms of the different adversities that came across them always made them doubt the extent to which whether it is worth the fight. The eventual gain has been how some of the individuals were able to overcome the adversities, the hurdles, the obstacles as they had a clear intent to overcome the "glass ceiling" and it made them keep persisting with what they want from their career pursuit and not to mention that at each and every step they kept. The impact that a role model or one who has gone through the system and has been able to reach the position and achieve the position that one has been able to acquire the way that one needs to be aware of in such a way that would enable one to go around in a way that helps to bring about the way that one would be expected to go about. The "glass ceiling" that obstructs one to not pursue certain way of going about since they do not see how one can end up pursuing their career.

\section{SUGGESTIONS AND RECOMMENDATIONS TO REDUCE "GLASS CEILING"}

The interview led towards the respondents being asked as to how they would be advising the upcoming generation of women whoare willing to be engaged in the work force and work hand in hand with their male counterpart while being a productive contributor in the work force with utility of the resources.

\section{a. Having faith in one's own abilities}

One of the biggest concern that women in general encounter is the fact that they keep doubting themselves and their work. The lack of acknowledgement, recognition and validation of their work from superiors and peers would help to solidify the confidence of the individual that they are capable of doing their work properly and the quality of their work is also of a certain standard that can easily compete with her contemporary coworkers and at the same time, the lack of how it makes one keep doubting the credibility of oneself thus it is pertinent that one never ends up being doubtful with regard to how one should go about her work and that she is competent and thus she is holding a position of power which she should cherish while working, going ahead.

\section{b. $\quad$ Being one's own support system}

The way how a woman in the academic sphere tends to break the "glass ceiling" where she is exposed to being scrutinized on multiple occasions for the sake of her career thus making it tough for the way how she goes about doing her work and she needs to have full faith and belief with respect to how the work she has taken up to fulfill her duties and in the course, it is pertinent that she always supports herself. The need for confidence on oneself has been mentioned by each of the respondents and they recognize how important it is for the individuals to recognize and value oneself and the belief in the fact that she has to trust herself in moving forward with the plethora of obstacles and hurdles that end up coming her way but if she is not resilient then it only becomes more difficult for herself to accomplish the goals that she has been aspiring to achieve.

\section{c. Being clear about one's entitlements and not compromising to voice oneself}

The biggest concern that a woman often ends up not being aware of is about her entitlements where she has a clear understanding as to what she is entitled to receive with respect to the work that she is involved and engaged with and what she needs to do in order to fulfill her duties and responsibilities while carrying the task in hand. The respondents also clearly pointed out that they had to ensure that their voice and opinions were put across and got the attention deserved.

\section{d. Being clear with regard to how one intends to go about in their career path}

The intention from a task and work has to be very discreet if a woman has to get her work accomplished in a proper way. The absolute synergy between the objective and execution of the work that one wishes to achieve has to be clear in the mind of the individual going about the work and not to mention the way in which one clearly understands that she requires being clear with respect to the career path that the individual wishes to accomplish and the need for her to be focused with regard to her aspiration can help to make an individual realize what she intends to achieve and what she can do tomake her wishes tobe accomplished in a positive way.

\section{e. Giving priority to one's own development}

The way how one goes about in making her career pursuit to be materialized makes it a tough choice where one who are not entirely sure that how they can accomplish the goals that they have set forth for oneself and it goes without saying that she has to make earnest effort to not only achieve their goals which perhaps is not only short term but extends to long term goals that enables theindividual toachieve the desired goals. The growth of an individual is a continuous process and one can never feel that in the Academic sphere there is an end with regard to the growth of an individual and when one seeks to go ahead in the chain of hierarchy thus she has to keep developing oneself in the course 


\section{FACTORS INFLUENCING GLASS CEILING FOCUS ON WOMEN ADMINISTRATION IN HIGHER EDUCATION IN MALAYSIA: A CRITICAL}

of her career path and also to ensure that there is enough scope and opportunity for her to move up the chain of hierarchy where the credibility of the individual and the quality of work is the foremost priority which makes her progress easier and since an individualisconstantlymaking anearnesteffort to goaboutinher course of career goals where one needs to ascertain and establish herself as possessing certain traits and quality that allows her work to speak for herself and the way how she manages toachievethe goals.

\section{f. Being vocal about any discomfort at any stage or} phase of life while pursuing a career

The extent to which a woman, her work and her opinions are undermined ends up making a woman feel dissociated in terms of the work that she is involved with and it is needless to say that it is a necessity for an individual that her opinion is given adequate and appropriate attention and importance that empowers a woman in being able to have an impact in a way that leads towards establishing that the way she is carrying out her work is something that is adding value and in a manner that does take into consideration that the way she is not being able to receive any of her deserving entitlements and the way how she is treated by her superiors i.e. supervisors, the peers that she works with and in the course receives any and all forms of support she needs for sure.

\section{CONCLUSION}

The prominence of "glass ceiling" in the academic sphere has been unanimously conceded by almost each of the respondents and they also recognized that on a case by case basis the individuals who have reached a certain position of power after breaking through the "glass ceiling" had their own struggles to deal with and had their own way of dealing with it as well. The way how an individual would deal with the impacts and effects of "glass ceiling" what they had to encounter and how they dealt with it acts to be like aprecedence that is expected to make the life of the upcoming generation who would be getting involved in the workforce so if they are not given an environment and a working culture that does not allow them to feel comfortable then there is no way that the future can be built in a manner where a woman would be feeling safe and secured in being involved to work along.

The contribution by approximately $50 \%$ of the population is pivotal to the way how the fabric of the society can work to make an optimum utilization of the resources at its disposal. The statement even though being true but has its own dynamics and manifestations, until and unless the various issues are not taken care of then it will be extremely difficult to make a cordial environment for the women and when she makes an earnest attempt to go against the general mainstream and the conventional narrative she has to get over a lot of obstacles since there are hurdles in context of society, family, workplace and its environment, the way how a woman goes about in accomplishing their career pursuit in the course of going about the way that they would want to achieve success in life.

Theentire paperhas been prepared toidentify the various ways how a woman encounters the ways in which she has to deal with "glass ceiling" in context of the academic administration and for a country like Malaysia that has its own position in accordance totheGenderDevelopmentIndex thusitexplores the ways in which women who have been able to cross through "glass ceiling" that they have encountered while progressing during their career pursuit to reach the position that they have been able to achieve and reach and they also put forth their personal experience in terms of the obstacles that they have come across and what they were able to do about the hurdles that enabled them to reach their feats and the ways how the impact and effect of the "glass ceiling" can be dealt by the women because they realize that the obstacles are an imminent hurdle that has to dealt with and it requires a lot of measures that focuses on the way how a woman needs to be aware of certain entitlements for themselves, the way how one has to realize that the most prominent factor to act in making a woman to be affected less due to how "glass ceiling" can work to make the life of a woman more difficult so the self-awareness and the realization that if they do not help themselves, no one can help them to progress forward in their life.

\section{REFERENCES}

1. Malhotra, S. (2010) "The equality illusion" Financial Express, Mar $07 \quad$ Available at http://www.financialexpress.com/news/the-equalityillusion/587681/0

2. Rosefed, R. A., Kallerberg, A.L. (1990). A cross national comparison of the gender gap in the income. American Journal of Sociology,, Vol. 96(1)

3. Hymowitz, C. and Schellhardt, T.D. (1986) "The glass ceiling: Why women can't seem to break the invisible barrier that block them from the top jobs" The Wall Street Journal, March 24

4. http://hdr.undp.org/en/composite/GDI

5. Kamau, N. A. (2001). The status of women and higher education management: A case study of one private university in Kenya. Unpublished M.A dissertation. Institute of Education, University of London

6. http://www.faqs.org/health/topics/8/Gender-roles.html

7. Smulders, A. E. A. (1998). Creating space for women: Gender linked factors.

8. O’Neil, D. A., Hopkins, M. M., and Bilimoria, D. (2008). Women'scareersatthestart of the $21^{\text {st }}$ century: Patterns and paradoxes. Journal of Business Ethics

9. Neuman W. (1998), True to Ourselves: A Celebration of Women Making a Difference, San Francisco: Jossey-Bass Publishers 